\title{
Unemployment and Vacancy in the Hong Kong Labor Market ${ }^{1}$
}

\author{
Charles Ka Yui Leung, Weslie Yuk Fai Chan \\ Chinese University of Hong Kong ${ }^{2}$ \\ Chung Yi Tse \\ University of Hong Kong ${ }^{3}$
}

February 1, 2000

\begin{abstract}
${ }^{1}$ We owe thanks to Rodney Chun and Chun-Wah Liu for helpful comments. Financial supports from a Shaw College and Chinese University Direct Grant (Leung) and a HKU URC grant (Tse) are gratefully acknowledged.

${ }^{2}$ Department of Economics, Chinese University of Hong Kong, Shatin, Hong Kong, tel: 852-2609-7158; fax: 2603-5805; email: charlesl@cuhk.edu.hk (Leung), s970129@mailserv.cuhk.edu.hk (Chan).

${ }^{3}$ School of Economics and Finance, University of Hong Kong, Pokfulam Road, Hong Kong, Tel: 852-2859-1035, fax: 2548-1152, email: tsechung@econ.hku.hk.
\end{abstract}




\begin{abstract}
This paper combines unemployment and vacancy data to analyze the efficiency of the Hong Kong labor market for the period 1976 to 1997. We confirm that the negative relationship between unemployment and vacancy, commonly known as the Beveridge curve, applies to the Hong Kong labor market. There was an inward shift of the Beveridge curve around 1982, which implies falling match frictions since then. We also find systematic evidence that Hong Kong has been close to full employment for on average, around eighty percent of unemployment in the period was due to structural and frictional unemployment with only twenty percent attributable to cyclical unemployment.

JEL Classifications: E24, J60, J63.
\end{abstract}

Keywords: Unemployment, vacancy, Hong Kong labor market. 


\section{INTRODUCTION}

With an average unemployment rate of only $2.83 \%$ for the period 1976 to 1997 , unemployment was not a major concern for Hong Kong. The Asian financial crisis was a watershed. The unemployment rate kept increasing after the onslaught of the crisis to the historical high of $6.7 \%$ in the first quarter of 1999 . Understandably, unemployment is consistently ranked as the most important concern by the Hong Kong public in recent opinion surveys. Economists too are starting to pay more attention to the Hong Kong unemployment problem. A more systematic analysis of the functioning of the Hong Kong labor market relating to unemployment in particular is certainly past due. In this paper, we use data on unemployment and vacancy for the period 1976 to 1997 to do just that. Since our sample ends in 1997, we cannot at this moment investigate the rising unemployment confronting Hong Kong since the onslaught of the Asian crisis. The results in this study may nevertheless serve as historical benchmarks for any future studies that investigate unemployment in the period concerned, beside providing a framework of analysis for any such studies.

Of course this paper is not the first one to study unemployment in Hong Kong. ${ }^{1}$ Our contribution lies in combining the information embedded in vacancy data with data on unemployment to form a more complete picture of the functioning of the Hong Kong labor market. To the best of our knowledge, previous investigations on unemployment in Hong Kong focus solely on unemployment data, missing out the information that vacancy data supply. The approach of combining data on unemployment and vacancy to study the labor market has a long history starting with the contribution of Beveridge (1944) who discovered a negative relationship between unemployment and vacancy and argued that full employment is at a point where the two

\footnotetext{
${ }^{1}$ See Suen $(1995,1996)$ for a comprehensive review of the Hong Kong labor market and for how the restructuring of the Hong Kong economy has affected employment in various sectors.
} 
are equal. ${ }^{2}$ To credit his contribution, the negatively-sloped unemployment-vacancy curve has since been called the Beveridge curve. The framework is now standard and in the last decade, much has been done on applying it to study the labor markets in many OECD countries.

Our main findings are as follows. First, we confirm that the negative relationship between unemployment and vacancy holds for Hong Kong from both time-series and cross-sectional data. And then we find that there was an inward shift of the unemployment-vacancy (U-V) curve around 1982. This represents a reduction in labor market frictions in the sense that more job matches are formed with the same number of job vacancies and unemployed workers. In contrast, during the same period of time, there were outward shifts of the $\mathrm{U}-\mathrm{V}$ curves in most OECD countries that imply deteriorating match frictions.

Under the premise that the natural rate of unemployment occurs at a point where unemployment and vacancy are equal, we find that nearly eighty percent of total unemployment can be attributed to labor market frictions. In comparison, substantially smaller portions of total unemployment originate from labor market frictions in most OECD countries. This finding is consistent with the fact that the Hong Kong economy was undergoing rapid restructuring from manufacturing to services in the period concerned.

We also uncover evidence that labor markets in the expanding sectors, such as Finance, Insurance and Real Estate are more efficient than the labor market in Manufacturing, a shrinking sector, in matching unemployed workers with job vacancies. Relatedly, we find that the unemployment-vacancy ratio and the capital-labor ratio is negatively correlated in Wholesale/Retail (which suggests that capital and labor are complements in that sector) while positively correlated in Manufacturing (which suggests that capital and labor are substitutes in that sector).

\footnotetext{
${ }^{2}$ More discussion to follow in the next section.
} 
The organization of the paper is as follows. In the next section, we provide a background discussion on the negative relationship between unemployment and vacancy and formally derive the relationship from a random matching model of the labor market a la Diamond and Blanchard (1989). Section 3 reports the empirical results. Some concluding remarks follow in section 4.

\section{BASIC CONCEPTS OF BEVERIDGE CURVE}

The negatively sloped relationship between unemployment and vacancy commonly referred to as the Beveridge curve is a well known and robust relationship. A summary survey of studies that report such a relationship in various countries taken out from Christl (1992) is presented in table $1 .^{3}$ Blanchard and Diamond (1989) notes that the position of the Beveridge curve is of much practical importance.

"The Beveridge curve has often been interpreted as a logical supplement to the Phillips curve. If the rate of change in money wages is a function of excess demand in the labor market, measured by the difference between the unemployment rate and the natural unemployment rate, the parameters of the U-V curve then determine the shape and the position of the Phillips curve."

Blanchard and Diamond's claim is based on the argument that the natural rate of unemployment occurs at a point where unemployment and vacancy are equal, a proposition first articulated in Beveridge (1944). Intuitively, when the number of job openings exceed the number of workers looking for a job, competition will bid up wages and vice versa. And when the two are equal, the labor market is in equilibrium in the sense that there exists neither pressure for wages to go up nor down. In this

\footnotetext{
${ }^{3}$ See Chan (1999) for a more detailed and updated survey.
} 
way, the position of the $\mathrm{U}-\mathrm{V}$ curve determines the trade-off between wage inflation and unemployment embedded in the Phillips curve.

More formally, say we have a Phillips curve

$$
\Delta w=\alpha\left(u^{*}-u\right)+\varepsilon
$$

where $w$ is log wage, $u^{*}$ and $u$ are respectively log natural unemployment and $\log$ actual unemployment and $\varepsilon$ a random disturbance term. For illustrative purpose, say the negatively-sloped Beveridge curve has the form

$$
u=a-b v
$$

where $v$ is $\log$ vacancy and $a$ and $b$ parameters governing the intercept and the slope of the Beveridge curve respectively with $b>0$. Defining natural or equilibrium unemployment as where unemployment and vacancy are equal

$$
u^{*}=\frac{a}{1+b} .
$$

Substitute the above into the Phillips curve

$$
\Delta w=\alpha\left(\frac{a}{1+b}-u\right)+\varepsilon
$$

This shows that the slope and the intercept of the Beveridge curve determines the intercept of the Phillips curve and hence the trade-off between unemployment and inflation.

The estimation of the Beveridge curve is a convenient mean to decompose unemployment into a structural and frictional component and a cyclical component. Equations (1) and (2) show that an estimate of the natural or equilibrium unemployment readily falls out from estimating the Beveridge curve. The knowledge of natural unemployment is obviously important for formulating monetary policies for a large country like the US. But even for a small open economy like Hong Kong that does 
not have the freedom to pursue independent monetary policies, it is still very useful for policy makers in formulating labor market policies. For example, if it were found that the bulk of actual unemployment is frictional and structural unemployment, policies designed to improve the flow of information in the labor market and to expand training programs may be the most appropriate. On the other hand, if much of unemployment were found to be unemployment in excess of natural unemployment, fiscal policies such as investment in infrastructure may be more appropriate.

In figure 1, we stretch two typical Beveridge curves. The intersection of the $45^{\circ}$ degree line and the Beveridge curve determines the natural or equilibrium unemployment. So what determines the position of the intersection, or more precisely the shape and position of the Beveridge curve. And why is there a negative relationship at all?

A negatively-sloped and convex U-V curve can be derived from a Diamond-MortensenPissarides ${ }^{4}$ job matching function, which postulates that the number of job matches formed in a given period is a function of the inputs to the job matching process - job vacancies and unemployed workers searching for jobs. The concept of the job matching function is analogous to the concept of the production function with successful job matches the output of a complex and time-consuming process that matches job vacancies and unemployed workers. Denote the number of successful job matches as $H$, we may write

$$
H=\alpha m(U, V)
$$

where $\alpha$ is an efficiency parameter and $m$ is the job matching function. The $m$ function is usually taken to be increasing, constant returns to scale and concave. We may summarize the assumptions on the $m$ functions as:

$$
m_{U}, m_{V} \geq 0
$$

\footnotetext{
${ }^{4}$ Blanchard and Diamond $(1989,1990)$ and Mortensen and Pissarides (1994).
} 


$$
\begin{aligned}
m(0, V) & =m(U, 0)=0 \\
\text { and } m_{U U}, m_{V V} & \leq 0
\end{aligned}
$$

It is typically assume that

$$
m(U, V)<\min \{U, V\}
$$

to capture the notion that the labor market is plagued with frictions and operates less than perfectly. The frictions may include the mismatch between the skills the unemployed workers possess and the skills demanded by firms, imperfect information flows in the labor market and imperfect mobility of workers.

For expositional purpose, assume that the number of matches are constant over time, then the slope of $\mathrm{U}-\mathrm{V}$ curve is given $\mathrm{by}^{5}$

$$
\frac{d V}{d U}=-\frac{\partial H / \partial U}{\partial H / \partial V}=-\frac{\alpha m_{U}}{\alpha m_{V}}=-\frac{m_{U}}{m_{V}}<0
$$

Intuitively, the slope of the $\mathrm{U}-\mathrm{V}$ curve derived from a matching function is analogous to that of the isoquant of a production function. The slope of the $\mathrm{U}-\mathrm{V}$ curve is simply the marginal rate of substitution between the two inputs - job vacancies and unemployed workers in "producing" successful job matches. We may further characterize the $\mathrm{U}-\mathrm{V}$ curve by differentiating the above

$$
\frac{d^{2} V}{d U^{2}}=\frac{-m_{U} m_{V V}+m_{V} m_{V U}}{m_{U}^{2}}
$$

Under the not implausible assumption that the two inputs are complements, i.e. $m_{V U}>0$, the above is positive, meaning that the Beveridge Curve is convex to the origin.

Consider what happens when matching efficiency improves via an increase in the parameter $\alpha$. The U-V curve will shift in for now the same number of matches may

\footnotetext{
${ }^{5}$ A negatively-sloped U-V curve can be derived under much weaker and more plausible assumptions. See Mortensen and Pissarides (1994) and Blanchard and Diamond (1990) for examples. The underlying intuition behind these derivations can all be traced to the discussion above.
} 
be "produced" with fewer unemployed workers and job vacancies. This suggests that an inward shift of the U-V curve represents an improvement in the working of the labor market in channeling job vacancies and unemployed workers into successful job matches. In the meantime, the intersection of the $45^{\circ}$ degree line and the $\mathrm{U}-\mathrm{V}$ curve will be at a lower level of unemployment. Not unexpectedly, improvements in matching efficiency will result in falling natural unemployment.

\section{EMPIRICAL RESULTS}

Now let us turn to the empirical evidence to see whether the discussion in the last section applies to the Hong Kong labor market. First, we will verify that a Beveridge curve of the right shape indeed exists in Hong Kong in both time-series and crosssectional data. Next, we will show that there is a significant inward shift of the Hong Kong Beveridge curve since 1982. Third, we will calculate the natural unemployment rate implied by the estimation of the Beveridge curve. Finally, we will show that a parameter measuring the state of the labor market in terms of the ease with which unemployed workers may find employment - the U-V ratio exhibits opposite correlations to capital intensity in two major sectors of the economy - Wholesale/Retail and Manufacturing.

\section{A. The Beveridge curve}

The first step in the analysis is to verify that the negative relationship between unemployment and vacancy in the Beveridge curve applies to Hong Kong. In figures 2 and 3 respectively, we plot the two time-series against time and one against each other. There exists a very discernible pattern that the two series move in opposite directions over time in the first figure. This implies that the two series should be strongly negatively correlated, and figure 3 confirms that this is indeed the case. 
Furthermore, figure 3 shows that the Beveridge curve is convex to the origin, as theory predicts it to be. More interesting is that the Beveridge curve appears to have shifted in since 1982. As noted in the last section, this implies falling match frictions and consequently an improvement in the working of the labor market.

Next we regress unemployment rate $U R$ against vacancy rate $V R^{6}$ to undertake a more systematic analysis of the relationship between the two series. To allow for a possible shift of the U-V curve, a dummy variable (DI82) with a value equal to one for observations after 1982 and 0 otherwise is inserted into the regression. The basic specification of the model is

$$
U R_{t}=a_{0}+a_{1} V R_{t}+a_{2} D I 82+\varepsilon_{t}
$$

where $\varepsilon_{t}$ represents the error term. A time trend is also added to the above in alternative specifications. We run OLS regressions on annual data from 1976 to 1997.7 The results are summarized in table 2. There emerges a negative and statistically significant relationship between unemployment and vacancy rates in all specifications that include vacancy rate as an explanatory variable. There are negative time trends, as well as a negative and statistically significant effect from the 1982 year dummy.

\footnotetext{
${ }^{6}$ The vacancy rate is defined as the number of job vacancies divided by the sum of employment and the number of job vacancies. Recall that the Beveridge curve can be interpreted as the isoquant of the job matching function and it governs the relationship between the levels of unemployment and vacancy. If the job matching function exhibits constant returns to scale, the same relationship also holds (approximately) between the rates of unemployment and vacancy. Hence regressing the rates of unemployment against vacancy is equivalent to regression the levels of unemployment against vacancy.

${ }^{7}$ Table 1 summarizes previous studies that estimate the Beveridge curve by regressing the vacancy rate against the unemployment rate. Since the vacancy rate may be correlated with the error term, the use of OLS may not be appropriate. Indeed, two and three stages least square were often employed in previous studies to fix the problem. Yet the results are not significantly affected. For simplicity, we stick with OLS regressions.
} 
Together, this suggests falling labor market frictions over time. The estimates in the fourth column imply a 0.75 percentage point fall in the unemployment rate for each vacancy rate since 1982 .

The improvement in matching efficiency may be due to a better match between the skills the labor force possesses and employers' demand perhaps because of rising educational attainments. There may have been improvements in information flows in the labor market. Improvements in transportation infrastructure and changes in demographics may also have helped. Investigating the contributions from each of these potential sources for improvements is beyond the scope of this paper but should be an worthwhile exercise to pursue.

Using aggregate time series data to estimate the $\mathrm{U}-\mathrm{V}$ curve may be problematic since it assumes that the whole economy acts as a single labor market which is a patently unrealistic assumption. To check the robustness of the negative relationship between unemployment and vacancy rates, we check whether it holds for cross-sectional data too. In figure 4, we plot sectoral unemployment rate against sectoral vacancy rate for the fourth quarter of 1996, where the sectors are Food and Beverage, Clothing and Footwear, Paper and Printing, Other manufacturing indus-

tries, Whole/Retail, Imports and Exports trades, Restaurant and Hotels, Transport, Storage, Communication, Financing, Insurance, Real Estate and Business services, Public Administration, Education, Medical and Other Health and Welfare Services and Other services. The figure shows a very clear negative relationship in which sectors that have low unemployment are sectors where there are abundant vacancies and vice versa.

\section{B. The Natural Unemployment Rate}

The next step in our analysis is to calculate the implied natural rate of unemployment, defined as the rate at which the number of unemployed workers and the number 
of job vacancies are equal. ${ }^{8}$ Previously, when the purpose of the analysis is merely to establish the existence of a Beveridge curve relationship between unemployment and vacancy, the precise functional form employed in the regression is probably immaterial. Now when the analysis is to calculate the natural rate of unemployment implied by the estimation of the Beveridge curve, the precise functional forms employed obviously may matter. Since there is no a priori compelling functional form to adopt, we now repeat the estimation under each of the following.

$$
\begin{aligned}
V R & =\alpha+\beta U R+\varepsilon, \\
\ln (V R) & =\alpha+\beta \ln (U R)+\varepsilon, \\
\frac{1}{V R} & =\alpha+\beta \frac{1}{U R}+\varepsilon .
\end{aligned}
$$

The results are summarized in table 3 where we carry out the estimation for the economy as a whole, as well as for individual board sectors of the economy. The negative relationship between unemployment and vacancy survives all three specifications for the aggregate economy and for most broad sectors except Construction, in which the relationship turns positive under one specification and is statistically insignificant in all. ${ }^{9}$

The implied natural rates of unemployment are reported in the last column of the table. ${ }^{10}$ Fortunately, in most sectors and for the aggregate economy, the rates implied by the three models do not differ too much. In particular, the economy-wide

\footnotetext{
${ }^{8}$ The simplest way to estimate the natural rate of unemployment for a given year is to take a simple average of unemployment rates over the past few years. This yields an meaningful estimate only when the natural rate is fairly constant over time and the economy has not experienced accelerating nor decelerating inflation throughout the entire period. Our estimation has the advantage that it is better motivated by theory and should be valid even when there has been accelerating or decelerating inflation throughout.

${ }^{9}$ There are only 8 observations for Construction and this may account for the disappointing results.

${ }^{10}$ The natural rate of unemployment is calculated as where $V R=U R$. Since $V R=$
} 
natural rate of unemployment is estimated to lie between 2.12 to 2.40 percent. Given that the average unemployment rate for the 1976 to 1997 period is 2.83 percent, on average, around 80 percent of the unemployment is due to structural and frictional unemployment. This is high compared to estimates for most OECD countries. For instance, Abraham (1983) finds that around sixty percent of the unemployment in the US is due to labor market frictions and Christl (1992) finds that the corresponding figure for Austria is about sixty-five percent.

The sectors differ considerably in the natural unemployment rates, with Finance, Insurance, Real Estate - a fast growing sector the lowest and Manufacturing - a shrinking sector highest. This suggests that growing sectors are more efficient in channeling job vacancies and unemployed workers into job matches.

\section{C. Unemployment-to-Vacancy Ratio}

The Unemployment-Vacancy ratio is a conveniently mean to measure the state of the labor market. Under a large U-V ratio, unemployed workers have considerable difficulty finding jobs, whereas firms will find it difficult to recruit workers under a small $\mathrm{U}-\mathrm{V}$ ratio. The ratio has great practical importance for policy makers too in deciding the appropriate policies to reduce unemployment. When the number of unemployed workers fall well below the number of job vacancies, the appropriate unemployment policies are policies designed to improve labor market information flows and policies designed to upgrade the skills of unemployed workers. Conversely, when the number of unemployed workers exceed well above the number of job vacancies, the appropriate policies are policies designed to encourage job creation.

Table 4 reports the average $\mathrm{U}-\mathrm{V}$ ratios for the aggregate and broad sectors of the economy. Hong Kong's aggregate unemployment-vacancy ratio was only 1.49

$\overline{\text { vacancy+employment }}$ and $U R=\frac{\text { unemployment }}{\text { unemployment+employment }}$, when $V R=U R$, we also have unemployment and vacancy equal to each other. 
on average from 1976 to 1997, and falls below 1 from 1987 to 1994 . Except for Transportation and Construction, all broad sectors were experiencing considerable labor shortage. This contrasts sharply with the results for many OECD countries. Abraham (1983) reports that the aggregate U-V ratio of the US was about 4 in the late seventies and early eighties. We plot the ratios for the aggregate and the broad sectors of the economy in figure 5 against time using the longest available time-series. All industries show a similar trend, with Construction and Wholesale/Retail more volatile than others. The apparent downward drift of the trends around the early to mid-eighties shows that the Hong Kong labor market has become tighter since then when compared to the earlier epoch.

\section{D. Relationship between $\mathrm{U}-\mathrm{V}$ ratio and $\mathrm{K}-\mathrm{L}$ ratio}

There are good economic reasons for the U-V ratio to be systematically related to capital intensity (as captured by the K-L ratio). In the short to medium run, it is not implausible to assume that the supply of workers in a given broad sector is relatively inelastic. Consider an increase in the capital stock. Holding employment constant, the K-L ratio will rise. If capital and labor are complements (substitutes), the increase in the capital stock will raise (lower) labor demand. More (less) jobs will be created to compete for the fixed pool of workers and in turn, the U-V ratio will go down (up). Hence if capital and labor are complements (substitutes), we would expect the U-V ratio and $\mathrm{K}-\mathrm{L}$ ratio to be negatively (positively) correlated.

Data availability only permits us to calculate the correlations in two broad sectors - Wholesale/Retail and Manufacturing. The correlations are respectively 0.508 and -0.765. These correlations are quite pronounced, suggesting that the relationships are reasonably robust. To see this more clearly, we plot the $\mathrm{K}-\mathrm{L}$ and $\mathrm{U}-\mathrm{V}$ ratios against each other for the two sectors in figures 6 and 7 respectively. It can be seen that there is a very clear positive relationship in Manufacturing and a very clear 
negative relationship in Wholesale/Retail. And this implies that capital and labor are substitutes in the former and complements in the latter.

\section{CONCLUSION}

In this paper, we report that the negative-sloped unemployment-vacancy Beveridge relation applies to the Hong Kong labor market. The inward shift of the Beveridge curve since 1982 implies an improvement in the working of the labor market. In future studies, we would like to investigate the sources for the improvement. The implied natural unemployment rate from the estimation of the Beveridge curve suggests that the bulk of unemployment in the period concerned is due to labor market frictions. To the best of our knowledge, this is the first systematic evidence that Hong Kong has been close to full employment. 


\section{APPENDIX}

\section{A1. Data Definitions and Sources}

\section{Employment, Unemployment, Vacancy and Labor force.-}

(a) Employed population: persons aged 15 and over who have been at work for pay or profit during the seven days before enumeration or who have had formal job attachment.

(b) Unemployed population: persons aged 15 and over who have not had a job, have not performed any work for pay or profit, have been available for work during the seven days before enumeration and have sought work during the thirty days before enumeration

(c) Labor force: the land-based civilian non-institutional population aged 15 and over who satisfy the criteria for inclusion in the employed population or unemployed population.

(e) Vacancies: unfilled, immediately available job openings reported by the establishment for which it is actively trying to recruit personnel on the survey reference date.

(f) Vacancy Rate: equal to the number of vacancies divided by the sum of the number of vacancies and the number of employed.

(g) Unemployment Rate: equal to number of the unemployed divided by the sum of the number of unemployed and the number of employed.

Sources:

(1) Quarterly Report of Employment, Vacancies and Payroll,

(2) Hong Kong Annual Digest of Statistics,

(3) Report on Labor Force Survey, 
(4) Report on Quarterly General Household Survey,

(5) Survey of Wholesale, and Retail and Import/Export Trades, Restaurants and Hotels.

\section{Capital stock.-}

The capital stock series is calculated from the investment series reported in Survey of Industrial Production and Survey of Wholesale, Retail and Import/Export Trades, Restaurants and Hotels using the perpetual inventory method as explained in King and Levine (1994) with a depreciation rate of 7 percent. 


\section{REFERENCES}

[1] Abraham, K.G., 1983, "Structural/Frictional vs Deficient Demand Unemployment: Some New Evidence," American Economic Review, 73, 708-724.

[2] — , 1987, "Help-Wanted Advertising, Job Vacancies, and Unemployment," Brooking Papers on Economic Activity, 0, 207-243.

[3] Beveridge, W., 1944, Full Employment in a Free Society, Allen and Unwin Press.

[4] Blanchard, O.J. and Diamond, P.A., 1989, "The Beveridge Curve," Brooking Papers on Economic Activity, 0, 1-60.

[5] — and —., 1990, "The Aggregate Matching Function," in P. Diamond (ed)., Productivity, Growth and Unemployment: Essays in Honor of Robert Solow's Birthday, Cambridge, MA: MIT Press.

[6] Budd, A., Levine, P. and Smith, P., 1988, "Unemployment, Vacancies and the Longterm Unemployed," Economic Journal, 98, 1071-91.

[7] Census and Statistics Department, various issues, Annual Digest of Statistics, Hong Kong Government Printer.

[8] _ - Report on Labor Force Survey, Hong Kong Government Printer.

[9] — Report on Quarterly General Household Survey, Characteristics of Labor Force, Hong Kong Government Printer.

[10] — Survey of Industrial Production, Hong Kong Government Printer.

[11] — Survey of Wholesale, Retail and Import/Export Trades, Restaurants and Hotels, Hong Kong Government Printer. 
[12] Chan, Y.F.W., 1999, The Hong Kong Labor Market: An Unemployment-Vacancy Analysis, Chinese University of Hong Kong, Unpublished Master Thesis.

[13] Christl, J., 1988, “An Empirical Analysis of the Austrian Beveridge Curve," Empirica, $15,327-50$.

[14] —, 1992, The Unemployment/Vacancy Curve, Theoretical Foundation and Empirical Relevance, Heidelberg: Physica-Verlag Press.

[15] Edin, P.A. and Holmlund, B., 1991, "Unemployment, Vacancies and Labour Market Programmes: Swedish Evidence," in S.F. Padoa (ed.) Mismatch and Labour Mobility, Cambridge University Press.

[16] Franz, W., 1987, "Hysteresis, Persistence and the NAIRU: An Empirical Analysis for the Federal Republic of Germany," in R. Layard and L. Calmfors (eds.), The Fight Against Unemployment: Macroeconomic Analysis from the Centre for European Policy Studies, MIT Press.

[17] Jackman, R., Layard, R. and Pissarides, C., 1989, "On Vacancies." Oxford Bulletin of Economics and Statistics, 50, 377-394.

[18] Jackman, R., Pissarides, C. and Savouri, S., 1990, "Labour Market Policies and Unemployment in the OECD," Economic Policy, 5, 449-90.

[19] King, R.G. and Levine, R., 1994, "Capital Fundamentalism, Economic Development, and Economic Growth," Carnegie-Rochester Conference Series on Public Policy, 40, 259-292.

[20] Layard, R. and Nickell, S., 1986 "Unemployment in Britain," Economica, 53, S121-69.

[21] Mortensen, D.T. and Pissarides, C., 1994, "Job Creation and Job Destruction in the Theory of Unemployment," Review of Economic Studies, 61, 397-415. 
[22] Suen, W., 1995, "Sectoral shifts: impact on Hong Kong workers," Journal of International Trade and Economic Development, 4, 135-152.

[23] — , 1996, "Employment and labor earnings," in H.C.Y.Ho and L.C. Chau (eds), The Hong Kong economy in transition, Asian Research Service. 
Table 1: Recent Empirical Studies of the Beveridge Curve

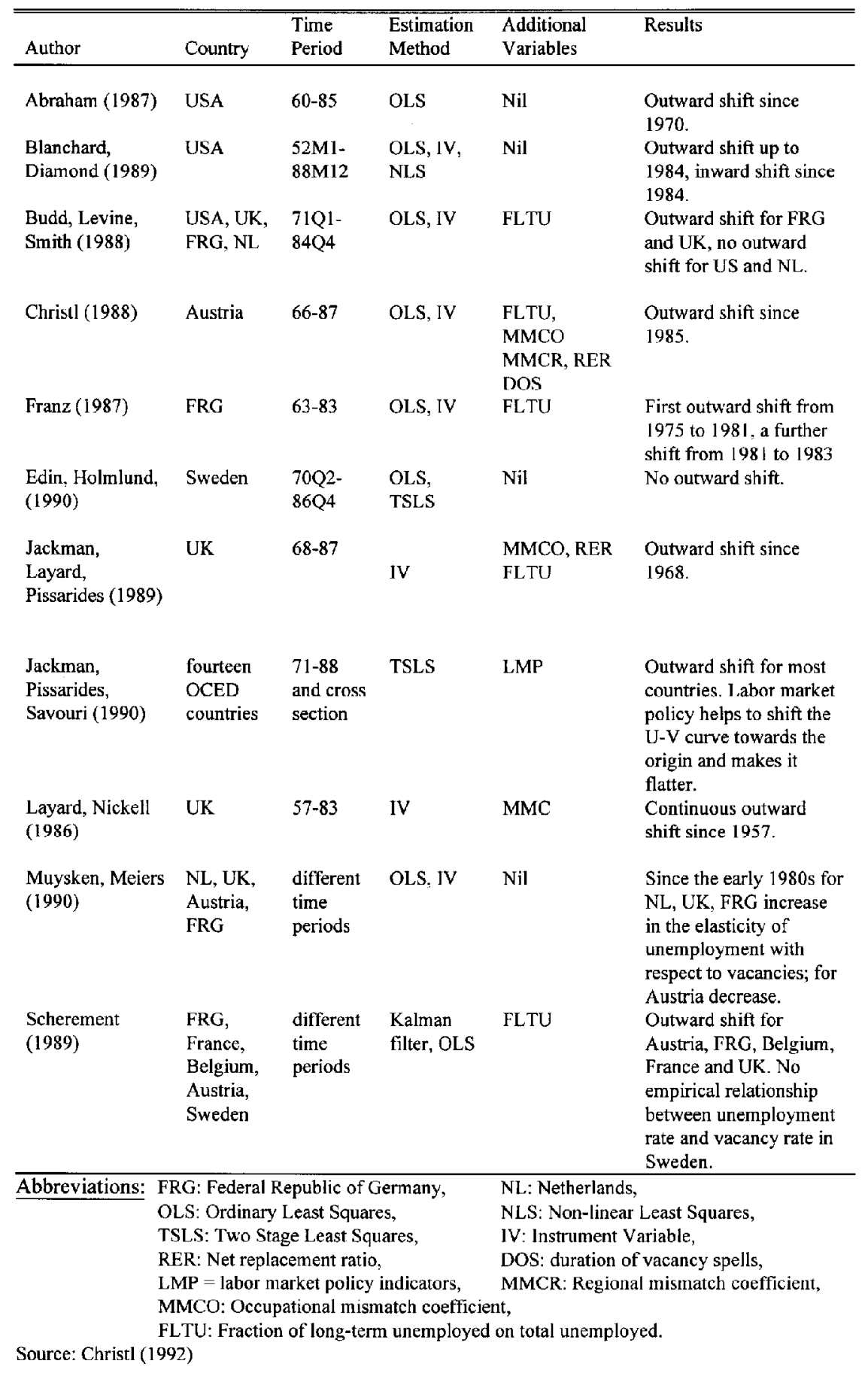


Table 2: Estimates of the Hong Kong Beveridge Curve (1976-1997) (Dependent variable: unemployment rate)

\begin{tabular}{lllll}
\hline \hline Equation & 1 & 2 & 3 & 4 \\
\hline Constant & 4.428 & 6.356 & $\begin{array}{l}6.362 \\
(12.012)\end{array}$ & $\begin{array}{l}6.594 \\
(15.690)\end{array}$ \\
& $(6.608)$ & $(14.604)$ & & -0.130 \\
Time Trend & & -0.929 & -0.091 \\
& & $(-7.405)$ & $(-5.567)$ & $(-3.592)$ \\
Vacancy Rate & -0.662 & -0.839 & & -0.899 \\
& $(-2.538)$ & $(-6.086)$ & & $(-6.855)$ \\
Dummy 1982 & & & -1.763 & -0.749 \\
& & & $(-5.817)$ & $(-6.892)$ \\
Adjusted R & & & 0.699 & 0.815 \\
DW & 0.206 & 0.785 & 1.118 & 1.763 \\
Residual Sum of & 19.583 & 5.039 & 7.042 & 4.102 \\
Squares & 0.377 & 1.541 & & \\
\hline
\end{tabular}


Table 3: Estimates of the Natural Rate of Unemployment

\begin{tabular}{|c|c|c|c|c|c|c|}
\hline Industry & $\hat{\partial}$ & $\hat{\beta}$ & $\bar{R}^{2}$ & $D W$ & $R S S$ & NUR \\
\hline \multicolumn{7}{|l|}{ Manufacturing } \\
\hline VR on UR model & $\begin{array}{l}5.2235 \\
(10.7918)\end{array}$ & $\begin{array}{l}-0.68781 \\
(-4.7427)\end{array}$ & 0.57325 & 1.3845 & 9.8737 & 3.09 \\
\hline InVR on InUR model & $\begin{array}{l}1.7221 \\
(12.2752)\end{array}$ & $\begin{array}{l}-0.65531 \\
(-5.2179)\end{array}$ & 0.62109 & 1.2096 & 0.95288 & 2.83 \\
\hline 1/VR on $\mathrm{I} / \mathrm{UR}$ model & $\begin{array}{l}0.57239 \\
(9.6241)\end{array}$ & $\begin{array}{l}-0.47938 \\
(-3.7812)\end{array}$ & 0.45387 & 1.0841 & 0.19865 & 2.58 \\
\hline \multicolumn{7}{|l|}{ Construction } \\
\hline VR on UR model & $\begin{array}{l}1.3091 \\
(1.944)\end{array}$ & $\begin{array}{l}0.0043835 \\
(0.070394)\end{array}$ & -0.16570 & 1.8085 & 2.1320 & 1.31 \\
\hline InVR on InUR model & $\begin{array}{l}0.45256 \\
(0.48733)\end{array}$ & $\begin{array}{l}-0.095230 \\
(-0.23563)\end{array}$ & -0.15597 & 1.5169 & 0.23649 & 1.51 \\
\hline I/VR on $1 / U R$ model & $\begin{array}{l}0.98407 \\
(3.5473)\end{array}$ & $\begin{array}{l}-1.3157 \\
(-0.57161)\end{array}$ & -0.10642 & 1.2594 & 0.56477 & 2.17 \\
\hline \multicolumn{7}{|c|}{ Wholesale and retail trade } \\
\hline VR on UR model & $\begin{array}{l}5.0997 \\
(14.577)\end{array}$ & $\begin{array}{l}-1.2832 \\
(-8.4749)\end{array}$ & 0.81572 & 1.7453 & 3.5990 & 2.23 \\
\hline InVR on InUR model & $\begin{array}{l}1.6610 \\
(12.9509)\end{array}$ & $\begin{array}{l}-1.3539 \\
(-8.4417)\end{array}$ & 0.81452 & 1.9457 & 0.89438 & 2.03 \\
\hline I/VR on $\mathrm{V} / \mathrm{UR}$ model & $\begin{array}{l}1.3100 \\
(8.5212)\end{array}$ & $\begin{array}{l}-1.3858 \\
(-5.0578)\end{array}$ & 0.60753 & 1.4823 & 0.72193 & 1.82 \\
\hline \multicolumn{7}{|l|}{ Transportation } \\
\hline VR on UR model & $\begin{array}{l}3.4487 \\
(10.7861)\end{array}$ & $\begin{array}{l}-0.33302 \\
(-5.5076)\end{array}$ & 0.66166 & 1.1519 & 3.9842 & 2.59 \\
\hline InVR on InUR model & $\begin{array}{l}1.9622 \\
(7.3036)\end{array}$ & $\begin{array}{l}-1.0192 \\
(-5.8247)\end{array}$ & 0.68703 & 1.7464 & 1.4981 & 2.64 \\
\hline I/VR on I/UR model & $\begin{array}{l}1.4608 \\
(7.5014)\end{array}$ & $\begin{array}{l}-2.8040 \\
(-4.0808)\end{array}$ & 0.51065 & 1.9055 & 1.4712 & 2.60 \\
\hline \multicolumn{7}{|c|}{ Finance, insurance and real estate } \\
\hline VR on UR model & $\begin{array}{l}4.8852 \\
(8.8917)\end{array}$ & $\begin{array}{l}-2.4204 \\
(-4.7468)\end{array}$ & 0.58941 & 0.72714 & 5.9512 & 1.43 \\
\hline InVR on InUR model & $\begin{array}{l}0.75625 \\
(9.7689)\end{array}$ & $\begin{array}{l}-1.0255 \\
(-4.3645)\end{array}$ & 0.54613 & 0.49871 & 1.3357 & 1.45 \\
\hline I/VR on I/UR model & $\begin{array}{l}0.96422 \\
(6.8682)\end{array}$ & $\begin{array}{l}-0.42321 \\
(-3.4440)\end{array}$ & 0.41997 & 0.46524 & 0.45836 & 1.48 \\
\hline \multicolumn{7}{|c|}{ Community and personal services } \\
\hline VR on UR model & $\begin{array}{l}4.3337 \\
(21.669)\end{array}$ & $\begin{array}{l}-0.78659 \\
(-9.9567)\end{array}$ & 0.86742 & 1.8169 & 1.3772 & 2.43 \\
\hline InVR on InUR model & $\begin{array}{l}1.4564 \\
(21.2219)\end{array}$ & $\begin{array}{l}-0.79852 \\
(-10.0961)\end{array}$ & 0.87061 & 2.1784 & 0.25829 & 2.25 \\
\hline 1/NR on I/UR model & $\begin{array}{l}0.82144 \\
(12.9518)\end{array}$ & $\begin{array}{l}-0.71025 \\
(-6.2313)\end{array}$ & 0.71607 & 1.8615 & 0.13084 & 2.08 \\
\hline \multicolumn{7}{|l|}{ Services $a$} \\
\hline VR on UR model & $\begin{array}{l}4.6500 \\
(17.1310)\end{array}$ & $\begin{array}{l}-1.0330 \\
(-9.2153)\end{array}$ & 0.83988 & 1.5666 & 2.4569 & 2.29 \\
\hline InVR on InUR model & $\begin{array}{l}1.5746 \\
(16.4343)\end{array}$ & $\begin{array}{l}-1.1351 \\
(-9.9002)\end{array}$ & 0.85842 & 2.0831 & 0.51232 & 2.09 \\
\hline ]/VR on I/UR model & $\begin{array}{l}1.1314 \\
(10.5135)\end{array}$ & $\begin{array}{l}-1.1510 \\
(-5.8970)\end{array}$ & 0.67855 & 1.5666 & 0.37684 & 1.61 \\
\hline \multicolumn{7}{|l|}{$\begin{array}{l}\text { All Industries } \\
\text { VR on UR model }\end{array}$} \\
\hline InVR on InUR model & $\begin{array}{l}3.1554 \\
(7.9720)\end{array}$ & $\begin{array}{l}-0.31566 \\
(-2.4053)\end{array}$ & 0.18558 & 0.66021 & 8.9131 & 2.40 \\
\hline \multirow[t]{2}{*}{ I/NR on $1 / \mathrm{UR}$ model } & $\begin{array}{l}1.1490 \\
(7.0127)\end{array}$ & $\begin{array}{l}-0.40458 \\
(-2.5694)\end{array}$ & 0.21058 & 0.75004 & 1.9112 & 2.27 \\
\hline & $\begin{array}{l}0.68484 \\
(7.9824)\end{array}$ & $\begin{array}{l}-0.45007 \\
(-2.4295)\end{array}$ & 0.18926 & 0.98001 & 0.54375 & 2.12 \\
\hline
\end{tabular}

a. Services consist of all of the above except manufacturing and construction. 
Table 4: Unemployment rate, vacancy rate and $\mathrm{U}-\mathrm{V}$ ratio

\begin{tabular}{llll}
\hline Industry/Period & $\begin{array}{l}\text { Mean rate of } \\
\text { Unemployment }\end{array}$ & $\begin{array}{l}\text { Mean rate } \\
\text { vacancy }\end{array}$ & Mean U-V ratio \\
\hline $\begin{array}{l}\text { Manufacturing } \\
\text { (1981-1997) }\end{array}$ & 3.05 & 3.13 & 1.33 \\
Construction & 10.27 & 1.35 & 9.5 \\
(1990-1997) & & \\
Wholesale, retail trades & 2.17 & 2.31 & 1.52 \\
(1981-1996) & & & \\
Transportation & 4.81 & 1.85 & 4.59 \\
(1981-1996) & & 2.39 & 0.57 \\
Finance, insurance and & 1.03 & & \\
real estate (1981-1996) & & 2.50 & 1.24 \\
Community and Personal & 2.33 & & \\
services (1981-1996) & & 2.32 & 1.45 \\
Services ${ }^{11}$ & 2.26 & & \\
(1981-1997) & 2.81 & & \\
All industries & & & \\
(1976-1997) & & & \\
\hline
\end{tabular}

${ }^{11}$ Services consist of all of the above except manufacturing and construction. 
Figure 1: Beveridge Curves

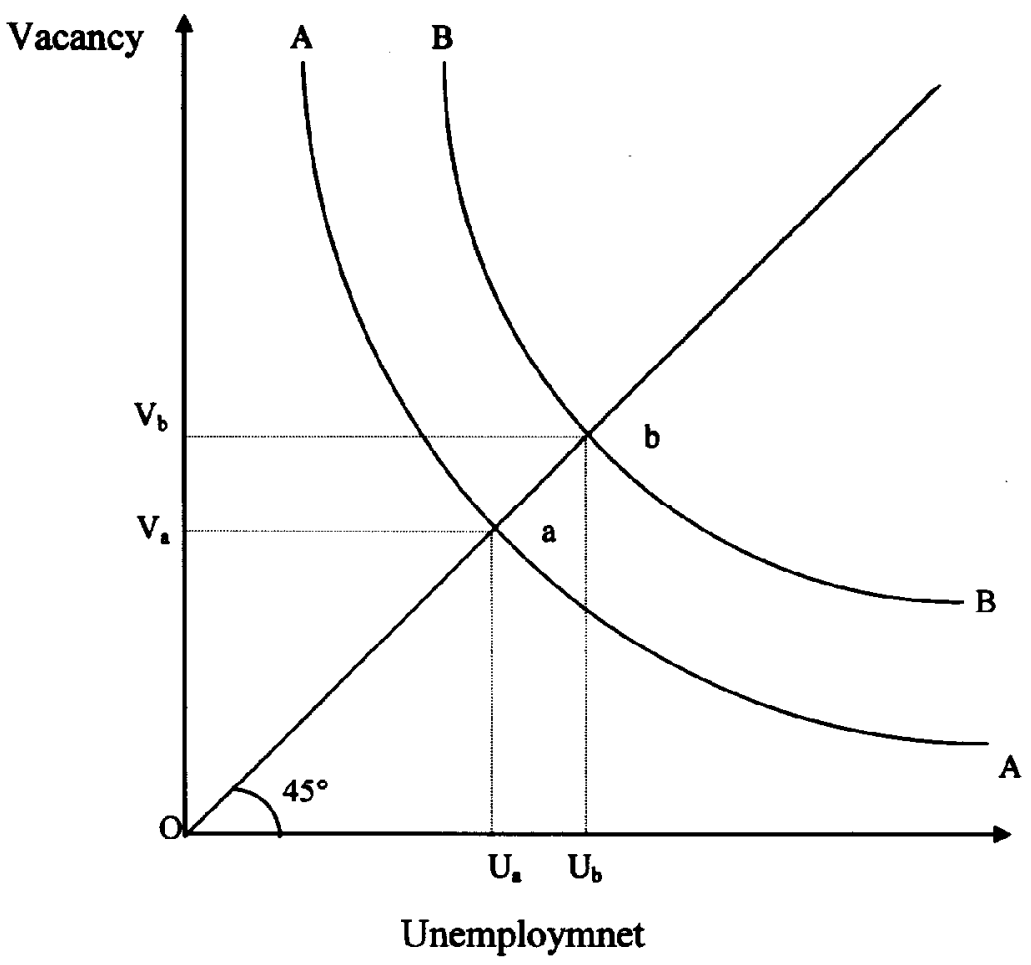


Figure 2: Unemployment and Vacancies in Hong Kong (1976-1997)

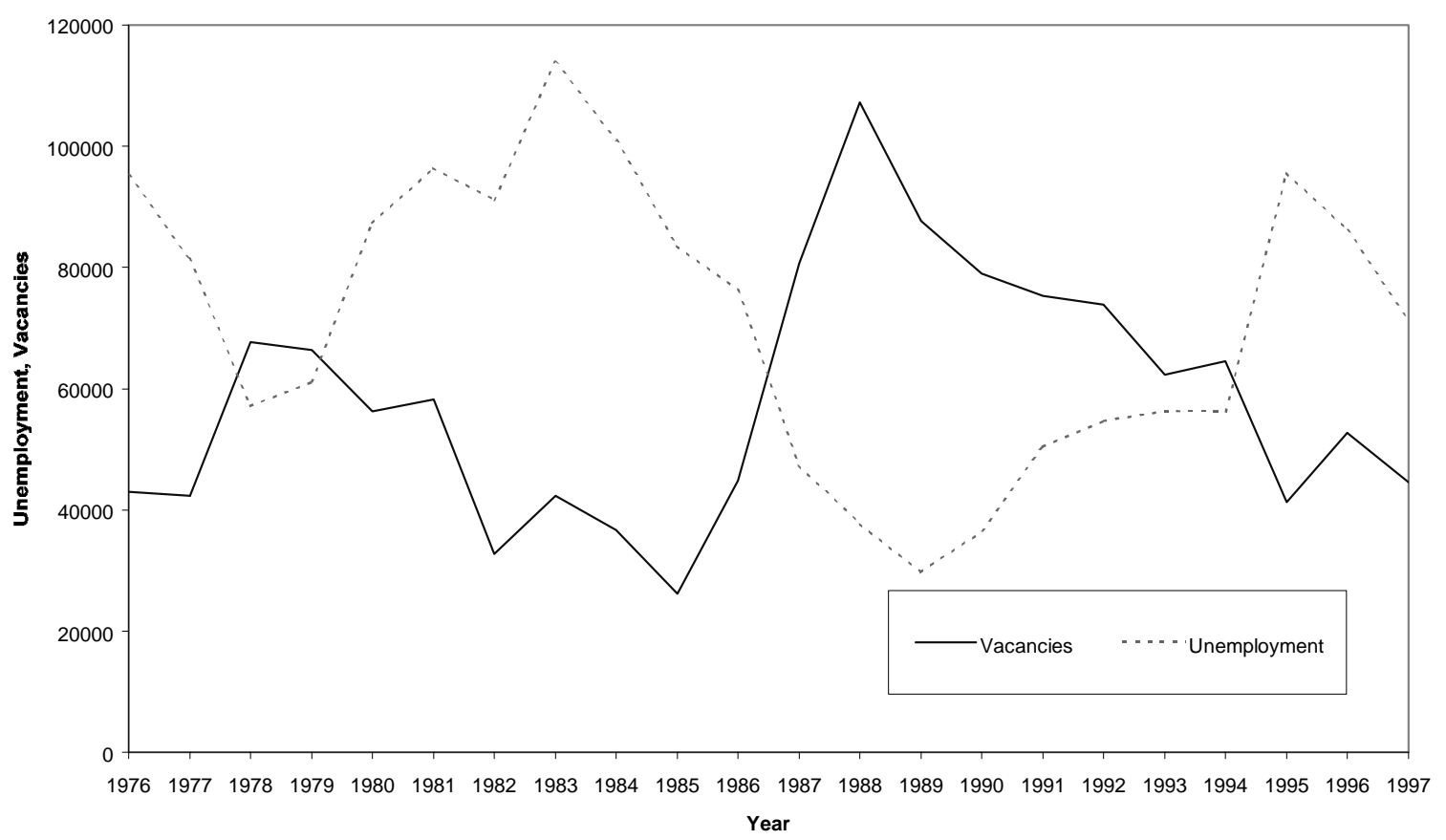


Figure 3: The Beveridge Curve of Hong Kong (1976-1997)

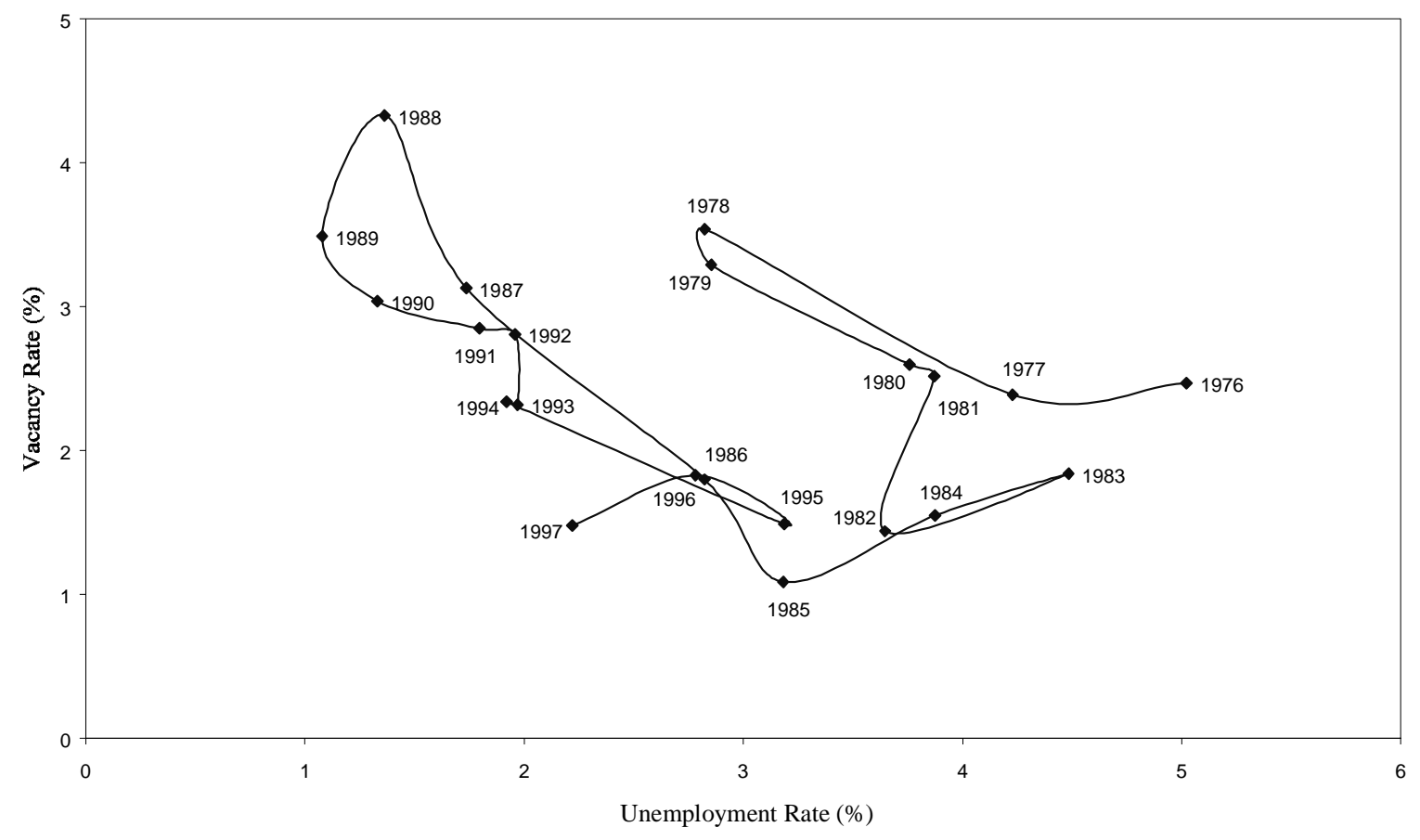


Figure 4: Cross Sectoral Beveridge Relationship in Hong Kong

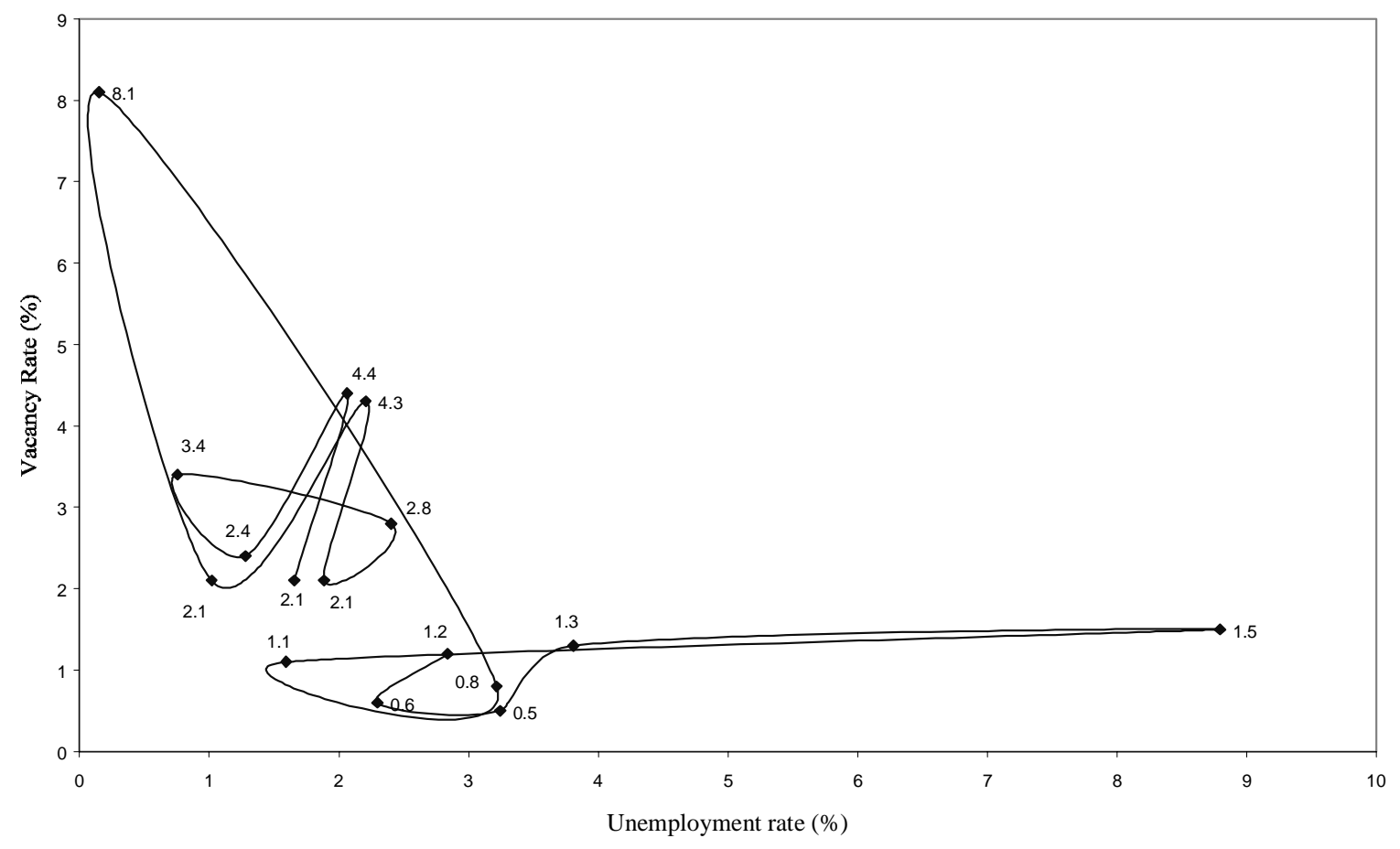


Figure 5: U-V ratio of broad sectors in Hong Kong

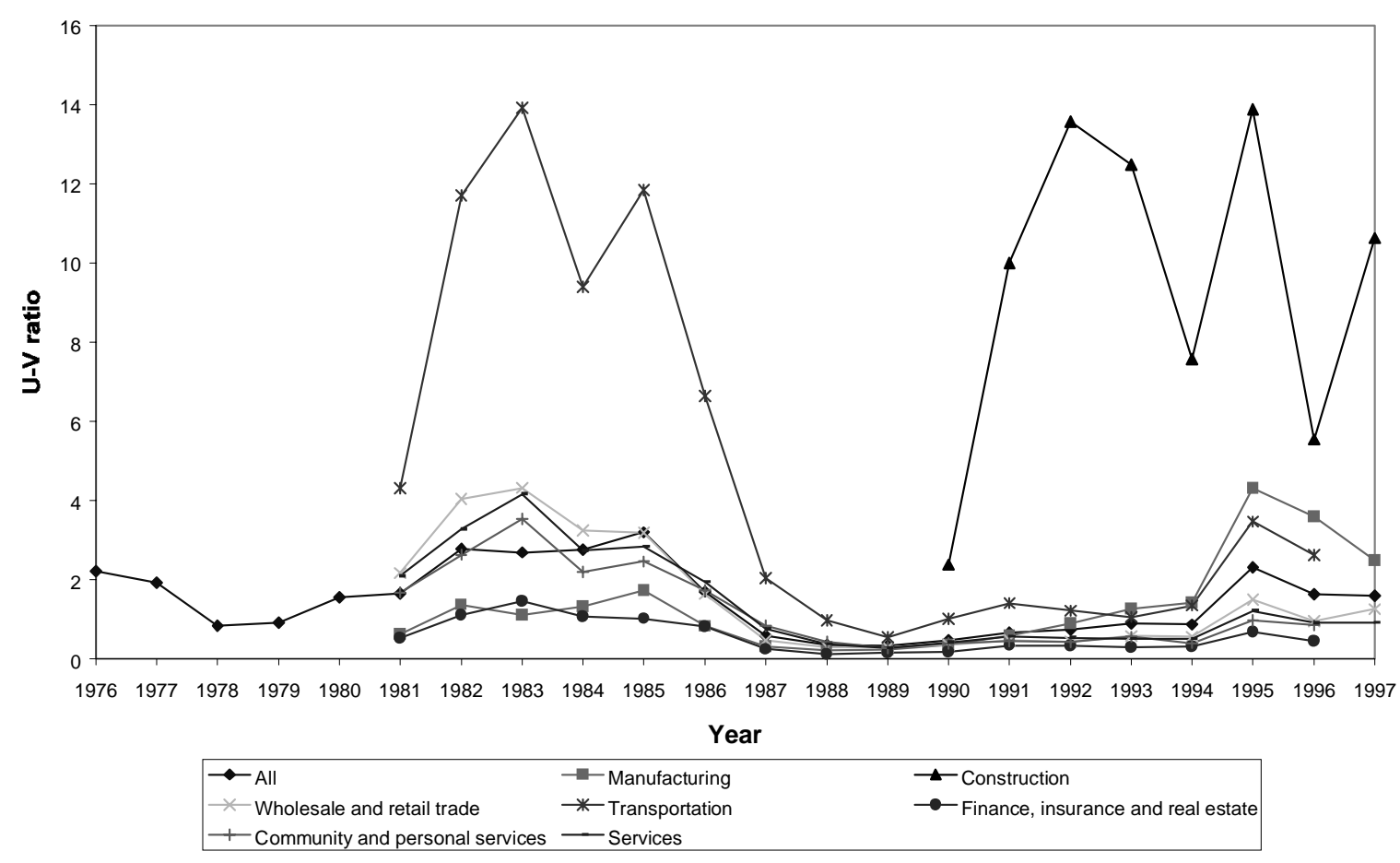


Figure 6: Correlation between U-V and K-L in Manufacturing (1981-1995)

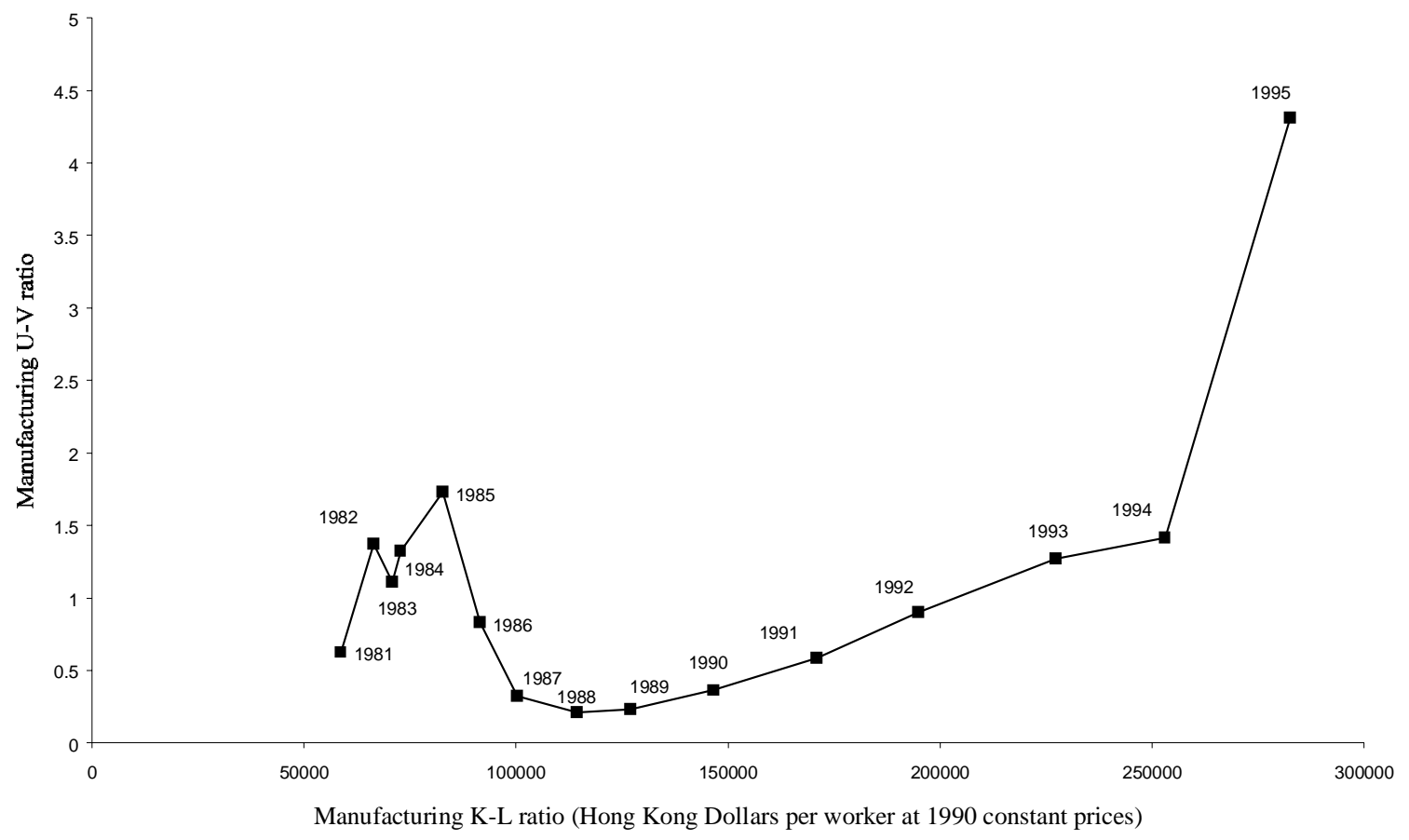


Figure 7: Correlation between U-V and K-L in Wholesale/Retail (1981-1994)

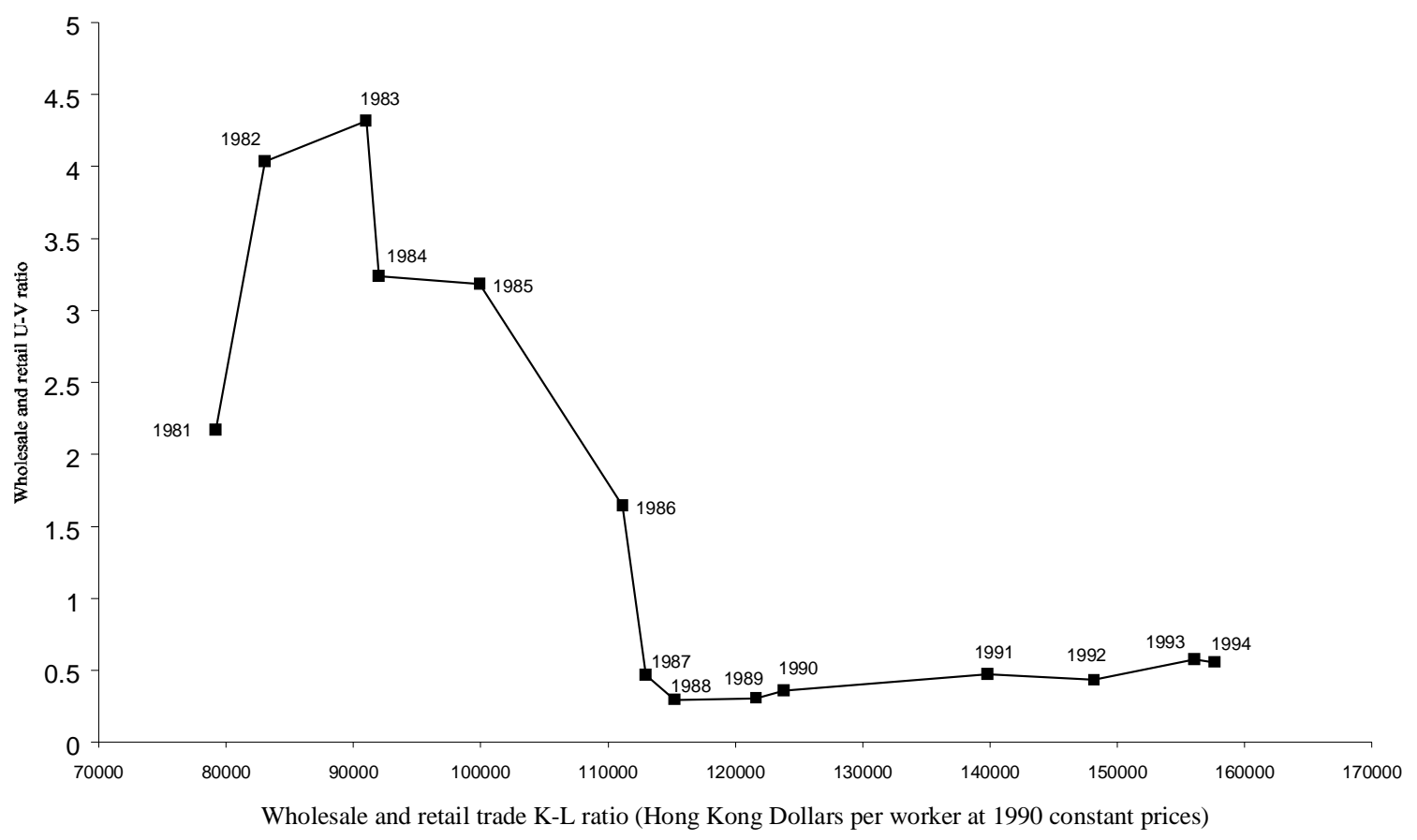

